\title{
Developing technology competences among Egyptian college of education students
}

\author{
Magdy M. Aly \\ Curriculum and Instruction Department, Faculty of Education, Ain Shams University, Cairo
}

\begin{abstract}
Colleges of education in Egypt are implementing initiatives to promote new and more effective teaching methods grounded in information technology and the improvement of teaching skills of undergraduate students in professional education programmes. The goals for participating faculty members are to integrate information technology competencies into not only the content of the courses that they teach, but also into their instructional methods of teaching. An initiative grounded in existing coursework, extant resources, and prior experience is described in this article. The effort provides a comprehensive, practical model for addressing the growing need for altering instructional methods to accommodate technology innovations for school personnel in meaningful ways.
\end{abstract}

Key words: competencies, information technology, standards, operational skills, professional use of technology

\section{INTRODUCTION}

The information age has created increasing needs for teachers and other school personnel at all levels of education to develop, use, and disseminate skills for including technology as the driving force behind preparing students for life in the 'real' world (Bailey, Ross and Griffin, 1996; Petrakis, 1996; Stanley, Linauer and Petrie, 1998). Technology has a significant foot in the door of Egyptian classrooms, and the schools will never again be the same (Funnell and Owen, 1992; Lowther, Lumley and Bailey, 1996; Mehlinger, 1996; Fisher, 1997; Bassoppo-Moyo and Morrison, 1998). Yet, most educators are provided with little training in how to use new technologies, so it is no surprise that many of them continue doing what they were doing

The original version of this chapter was revised: The copyright line was incorrect. This has been corrected. The Erratum to this chapter is available at DOI: 10.1007/978-0-387-35615-0_52 
rather than spending time learning how to use the innovations that are being provided for them (Hunt, 1995; Bailey, Ross and Griffin, 1996; Furst-Bowe, 1996; Hill and Somers, 1996; Ley, 1997; Stanley, Linauer and Petrie, 1998). Too often, technology innovations go unnoticed, ignored, or seldom used in today's schools; and, the effects of failing to keep up continues to downgrade the Egyptian educational system. The exclusion of information technology from the processes of planning, managing, and implementing curriculum innovations means that change in education is moving at a snail's pace and serves to maintain stagnant, sometimes mediocre instruction as the rule in efforts to 'reform' the schools (Morton, 1996).

There is a growing and continuing need for systematic efforts to infuse instructional technology in relevant ways in all professional education programmes preparing administrators, teachers, and counsellors (Otter, 1992; Kitagaki, 1995; Hill and Somers, 1996; Northrup and Little, 1996;). The scope of skills, attitudes, and knowledge is changing rapidly, and there is far too much for anyone to retain more than a small part. Therefore there is little value in storing up large quantities in memory, as was the aim of traditional education. Instead, what the knowledge society requires is, according to Beriter (1997):

1. Just-in-time delivery of knowledge that is up-to-date and appropriate to the task at hand.

2. Skills in knowledge search and retrieval.

3. Thinking skills and creativity.

4. Life-long readiness to learn and unlearn.

Like most conventional wisdom, this has powerful commonsense appeal. So what is wrong with it? Almost everything. To wit, although knowledge is increasing rapidly, very little of it becomes obsolete. The principal determinant of learning is what the learner already knows about the subject. Successful knowledge search depends on extensive and well-organised knowledge of the domain being searched. Expertise, including creative expertise, depends on deep intuitive understanding of the principles, problems, and tools of a domain. It is doubtful whether there are learnable thinking skills that can be acquired independently of sustained work in a field. Little is known about how to foster a life-long readiness to learn or even what this would mean. Love of learning should not be confused with readiness to tackle problems at the edge of one's competence. The only new idea is just-in-time knowledge delivery. The rest have been part of conventional educational wisdom for half a century. 


\section{EDUCATING TEACHERS FOR A KNOWLEDGE SOCIETY}

Children may be growing up in a digital media culture, but this does not mean they are growing up in a knowledge culture. Some are by virtue of a family or community that puts them on familiar terms with knowledge work. For many young people, however, schooling provides the only accessible entry point into a knowledge society. For them, teachers are indispensable agents of enculturation. This raises the question of how teachers can be expected to initiate students into a culture that they have not grown up in themselves. Add to this the built-in bias of teaching toward viewing knowledge as a property of students' minds, and we have the makings of a classic 'you can't get there from here' situation. Pre-service teacher education seems to be our best hope for introducing the needed cultural change.

\section{PROJECT DESIGN AND WORKPLAN}

The first step in successful implementation of any innovation is commitment on the part of student teachers, the subjects of the case study who are going to be trained to use information technology to enhance instruction during their teaching practice. For purposes of this effort, technology not only included computers but also computer networks and telecommunications, multimedia and hypermedia, camcorders and VCRs, instructional television and interactive video, CD-ROM and videodisc players, graphing calculators and video microscopes, telephone and voice mail technologies. The goals of the effort were:

1. To enhance basic and advanced information technology knowledge and productivity of students related to computer operating systems, word processing, spreadsheet programming, data base management, page layout and design, internet resources and use, presentation software, statistics and data processing, and instructional design courseware.

2. To develop instructional modules to help student teachers infuse information technology content into the teaching and learning processes that are the foundation of all professional education coursework.

3. To evaluate improvements in student teachers' competence and productivity that result from these efforts to enhance technology use in instruction. Responsibility for designing, implementing, and co-ordinating this response was assigned to a team of three people, myself (the researcher), a computer specialist, and one of the school teachers. Five overall goals were taken into consideration to:

a) clarify and refine technology, 
b) describe and define competencies,

c) articulate curriculum linkages,

d) acquire necessary information technology resources,

e) develop subject competence,

f) assess subject competence.

Members of the team organised and chaired a series of task forces to design, implement, and evaluate subject development activities related to each of five implementation objectives. To ensure adequate representation of the perspectives of those who would be affected by the activities, each task force included an appropriate mix of three groups of student teachers, where each group was grouped into three subjects who were directly involved in teaching practice. The design and workplan for implementation objectives are described below.

\section{TECHNOLOGY COMPETENCIES}

Two clusters of technology competencies served as overall guiding principles in developing learning objectives. Basic competencies represented entry-level skills related to basic computer operation, and the use of an array of software that supports and enhances professional productivity. Advanced competencies extended the application of basic competencies to teaching of student teachers. Significant overlap existed between these competencies and those identified as recommended foundations in technology for all student teachers by the International Society for Technology in Education. Basic and advanced technology competencies that student teachers were expected to have and use in their teaching practice included knowledge and skills in the following areas: computer operating systems; setup; word processing and introductory desktop publishing; graphing; data bases; networking; telecommunications; media communications; and multimedia integration. Advanced information technology competencies enable student teachers to use multiple forms of technology to enhance learning in their classrooms (for example, using school television resources to support teaching, using technology tools that are specific to a discipline, using technology to design and manage learning environments and resources) and finally internet skills.

\section{CURRICULUM ARTICULATION}

To support the development of information technology competencies among student teachers, a second task force developed a course-by- 
competency matrix that identified which competencies ought to be developed, enhanced, and applied in each course or other instructional activity in each professional education programme (i.e. elementary, middle, secondary). Each course in the college was evaluated relative to each competency to determine goodness-of-fit between the current curriculum and the intended technology-enhanced agenda. This activity served as the basis for all subsequent planning and implementation efforts. This provided a conceptual and logical base on which to evaluate existing activities, identify information technology instructional needs, and plan student teachers' development efforts.

\section{RESOURCES AND FACILITIES}

In collaboration with the college's Information Technology Centre (ITC), a third task force developed policies, procedures, descriptive materials, and other mechanisms to ensure that student teachers had access to the technology resources and facilities they needed to develop, enhance, and apply their growing repertoire of instructional technology competencies. These facilities and resources included:

1. Networked desktop computers in faculty offices.

2. An instructional technology classroom with five PC computers, instructional workstation, ceiling mounted sound and video projection equipment, a colour scanner, and networked laser printers.

3. A room with networked video cameras and VCRs, a roof-mounted satellite dish for TV reception.

4. One model classroom for teaching methods of English courses. It has four computers, instructor's workstation, portable projection equipment, and networked laser printer.

The task force and college Information Technology Centre continuously monitor resources and carry on additional efforts to address needs required to maintain, enhance, and expand information technology capabilities. In addition to a portion of the college's operating budget, resources are being sought from internal sources (i.e. a university student computing fee).

\section{STUDENT COMPETENCIES - ASSESSMENT AND DEVELOPMENT}

A task force reviewed the competencies and developed a second survey instrument (available upon request) for use in evaluating students' 
perceptions of their abilities within broad areas (for example, word processing, communications, desktop publishing). This information served a needs assessment function and provided baseline data for subsequent formative and summative evaluations. Analyses of these data led to another task force to the design, development, selection, acquisition, and modification of an array of methods, programs, activities, materials, and other mechanisms - some 'course-imbedded' and others 'stand-alone' - by which students could develop and enhance their mastery and use of the expected information technology competencies. These same assessment protocols, as well as a portfolio assessment procedure currently in the conceptual stage of development, were used within the college for determining and documenting both formatively and summatively the degree to which students have and use the basic and advanced technology competencies (and any others refined or added in the future) in their professional education courses and in their own teaching.

\section{FORMATIVE EVALUATION AND FEEDBACK}

Using appropriate models (for example, Kirkpatrick's four levels of evaluation), data were collected to evaluate the efforts to achieve the five implementation objectives and the overall goals for infusing information technology content in existing and planned teacher education curricula and classrooms. Formative evaluation reports were prepared at the end of each semester and these evaluation data were used in a feedback loop to refine the five implementation objectives and the associated activities. A faculty member within the College of Education with extensive experience in quantitative and qualitative evaluation methods was responsible for overseeing the design, execution, and reporting of this aspect of the project.

A pre-test/post-test one-group design was used to address questions about attitude and knowledge; an expertise-based evaluation was conducted to address questions about the value of products (Gall, Borg and Gall, 1996). A total of nine student teachers, whose work was reported as case studies, participated in the proposed instructional activities during the first semester started in September 2001 until mid-December 2001.

\section{CONCLUSIONS AND RECOMMENDATIONS}

The project this paper describes addresses the need for a common theme in a college of education grounded in modelling, and providing instruction in the educational use of technology, by illustrating how one college of 
education is enhancing basic and advanced information technology knowledge and productivity of student teachers. This goal is being achieved by following a model emphasising careful planning and evaluating of improvements in competence and productivity that result from enhanced information technology instruction. The following benefits have been or are expected to be accrued:

1. Systemic change within the college concerning the ways in which student teachers teach and manage instruction.

2. Enhancement of the information technology competencies for participating student teachers in a non-threatening manner.

3. The skills of student teachers to use information technology as an instructional tool in the schools are not taught in isolation but are integrated into coursework across the teacher preparation curriculum.

4. Assisting pre-service student teachers to master competencies for the infusion of information technology into their professional activities.

5. Preparation of a set of instructional modules for use in developing and extending the information technology skills of student teachers.

6. Preparation of innovative, computer-assisted assessment methods to determine the mastery of specific information technology competencies.

7. Preparation of continuing education workshops showing student teachers how and when to apply information technology to specific content and skill areas in the curriculum.

8. Making student teachers aware of the range of educational applications of information technology, including ones to which the schools may not as yet have access.

9. Building excitement and increasing anticipation of student teachers for the use of information technology to enhance instruction in schools.

\section{REFERENCES}

Bailey, G.D., Ross, T. and Griffin, D.L. (1996) Barriers to curriculum-technology integration in education. Educational Considerations, 23, (2), 14-17

Drucker, P. (1993) Post-capitalist society. New York: Harber Business

Fisher, M.M. (1997) The voice of experience: In-service teacher technology competency recommendations for pre-service teacher preparation programs. Journal of Technology and Teacher Education, 5, 139-147

Funnell, P. and Owen, J. (1992) Developing and measuring competence. Aspects of Educational and Training Technology Series, 25, 27-32

Furst-Bowe, J.A. (1996) An analysis of competencies needed by trainers to use computerbased technologies and distance learning systems. Performance Improvement Quarterly, 9, (4), 57-78

Gall, M.D., Borg, W.R. and Gall, J.P. (1996) Educational research (6th ed.). White Plains, NY: Longman Publishers 
Hill, R.B. and Somers, J.A. (1996) A process for initiating change: Developing technology goals for a college of education. Journal of Teacher Education, 47, 300-306

Hunt, N. (1995) Bringing technology into the pre-service teaching field experience. Computers in the Schools, 11, (3), 37-48

Kitagaki, I. (1995) Technology literacy in the immediate future and educational technology. Journal of Educational Technology Systems, 23, 369-381

Ley, K. (1997) Facing NCATE review or just looking for technology standards? TechTrends, 42, (4), 41-42

Lowther, D.L., Bassoppo-Moyo, T. and Morrison, G.R. (1998) Moving from computer literate to technologically competent: The next educational reform. Computers in Human Behavior, 14, 93-109

Lumley, D. and Bailey, G.D. (1996) Creating staff development programs: A leadership perspective. Educational Considerations, 23, (2), 9-13

Mehlinger, H.D. (1996) School reform in the information age. Phi Delta Kappan, 77, 400-407

Morton, C. The modern land of Laputa: Where computers are used in education. Phi Delta Kappan, 77, 416-419

Northrup, P.T. and Little, W. (1996) Establishing instructional technology benchmarks for teacher preparation programs. Journal of Teacher Education, 47, 213-222

Otter, S. (1992) Developing and measuring competence. Aspects of Educational and Training Technology Series, 25, 99-100

Petrakis, E. (1996) Using a portfolio to assess preservice teachers' technology competence. Journal of Computing in Teacher Education, 13, 12-13

Stanley, R.B., Lindauer, P. and Petrie, G. (1998) Factors that influence teachers' use of computer technology. ERS Spectrum, 16, (3), 42-46

\section{BIOGRAPHY}

Magdy M. Aly is associate professor of curriculum and EFL instruction at Ain Shams University, Cairo, Egypt. He also teaches educational technology, EFL courses and teaches at different colleges and institutes in Egypt. He runs different training courses in collaboration with the Ministry of Education in Egypt, and has also worked in Saudi Arabia. 